\title{
Communication
}

\section{Hepatoprotective Effects of Extract of Helicteres hirsuta Lour. on Liver Fibrosis Induced by Carbon Tetrachloride in Rats}

\author{
Dac Thang Hoang ${ }^{1}$, Thi Thu Hien Truong ${ }^{1, *}$, Ngo Viet Duc ${ }^{2}\left(\right.$, , Le Tuan Anh Hoang ${ }^{2, *}$, Thi Thao Do ${ }^{3}{ }^{(0)}$, \\ Le Ba Vinh ${ }^{4, *}$, Seo Young Yang ${ }^{5}$, Gao Dan ${ }^{6}$ and Le Tuan Anh ${ }^{7}$ (i) \\ 1 Centre for Toxicology and Radiology Teaching and Research, Vietnam Military Medical University, 160 Phung \\ Hung, Ha Dong, Hanoi 100000, Vietnam; thangk20hvqy@gmail.com \\ 2 Center for Research and Technology Transfer, Vietnam Academy of Science and Technology (VAST), \\ 18 Hoang Quoc Viet, Hanoi 100000, Vietnam; ngovietduc.cretech@gmail.com \\ 3 Institute of Biotechnology, VAST, Hanoi 100000, Vietnam; thaodo@ibt.ac.vn \\ 4 Institute of Marine Biochemistry, VAST, Hanoi 100000, Vietnam \\ 5 Department of Pharmaceutical Engineering, Sangji University, Wonju 26339, Korea; syyang@sangji.ac.kr \\ 6 College of Pharmacy, Chungnam National University, Daejeon 34134, Korea; dangao@gmail.com \\ 7 MienTrung Institute for Scientific Research, VAST, 321 Huynh Thuc Khang, Hue City 52000, Vietnam; \\ letuananhbotany@gmail.com \\ * Correspondence: truonghientruong@gmail.com (T.T.H.T.); hltanh@ctctt.vast.vn (L.T.A.H.); \\ vinhrooney@gmail.com (L.B.V.)
}

Citation: Thang Hoang, D.; Hien Truong, T.T.; Viet Duc, N.; Anh Hoang, L.T.; Do, T.T.; Vinh, L.B.; Young Yang, S.; Dan, G.; Tuan Anh, L. Hepatoprotective Effects of Extract of Helicteres hirsuta Lour. on Liver Fibrosis Induced by Carbon Tetrachloride in Rats. Appl. Sci. 2021, 11, 8758. https://doi.org/10.3390/ app11188758

Academic Editors: Ivelina Desseva and Dasha Mihaylova

Received: 11 August 2021

Accepted: 17 September 2021

Published: 20 September 2021

Publisher's Note: MDPI stays neutral with regard to jurisdictional claims in published maps and institutional affiliations.

Copyright: (c) 2021 by the authors. Licensee MDPI, Basel, Switzerland. This article is an open access article distributed under the terms and conditions of the Creative Commons Attribution (CC BY) license (https:/ / creativecommons.org/licenses/by/ $4.0 /)$.
Abstract: Helicteres hirsuta Lour. is a traditional Vietnamese medicine for treating chronic liver diseases such as cirrhosis and liver cancer. Many in vitro and in vivo experiments have demonstrated that the extracts and isolated compounds from $H$. hirsuta have diverse pharmacological activities, including antioxidant, anti-inflammatory, and anti-cancer effects. However, the hepatoprotective effects have not been reported until now. Therefore, the methanolic and ethanolic extracts of the aerial part of the H. hirsuta L. (HHM and HHE-1/1) were examined on liver fibrosis induced by carbon tetrachloride $\left(\mathrm{CCl}_{4}\right)$ in rats for the first time. The results revealed that all the livers of the model group had stage F4 cirrhosis; the group that received silymarin, and HHM and HHE-1/1 had milder liver damage cirrhosis stage F1-F2 which implies that the methanolic and ethanolic extracts of $H$. hirsute have a definite advantage in the development of food or oral medications for hepatoprotective activity.

Keywords: Helicteres hirsuta; hepatoprotective activity; cirrhosis; carbon tetrachloride; acute toxicity

\section{Introduction}

Cirrhosis is the last stage of chronic liver disease. Cirrhosis prevention and treatment is a problem of medicine. Many traditional medicine remedies have proven effective in the prevention and treatment of cirrhosis [1]. Free radicals damage liver cell membranes and lipid-oxidizing releases fibrous mediators, which in turn activate the hepatic stellate cell and other fibrous cells [2], resulting in fibrosis of the liver and cirrhosis. Medicinal herbs have been identified as rich sources of natural products with hepatoprotective activity.

According to traditional Vietnamese medicine, $H$. hirsuta is used to manage various ailments such as boils, pain relief, detoxification, dysentery, flu, smallpox, measles, malaria, snakebites, and especially liver diseases [3] such as cirrhosis, and liver cancer. Phytochemical investigation revealed that the major chemical constituents in H. hirsuta are lignans, diterpenoids, flavonoids, quinones, and triterpenoids. Some studies also show that H. hirsuta extract has diverse pharmacological effects, including antioxidant, anti-inflammatory, and anti-cancer in vitro [4-6]. However, at present, the pharmacological effects of the treatment of liver diseases of this plant have not been studied.

In the course of our continuous study on medicinal plants in Vietnam [7-9], this research was conducted to determine the preventive practical effects against fibrosis in 
experimental animals of $H$. hirsuta extracts. The obtained results showed all the livers of the model group had stage F4 cirrhosis; the group that received silymarin and HHM and HHE-1/1 had milder liver damage cirrhosis stage F1-F2. The results imply that the methanolic and ethanolic extracts of $H$. hirsute have a definite advantage in the development of food or oral medications for hepatoprotective activity. The study results are the basis for recommending further studies on the mechanism of hepatoprotective action and other pharmacological effects of this medicinal herb.

In order to isolate and evaluate the hepatoprotective effects of the extract of $H$. hirsuta, this study mainly studied the total methanol $(\mathrm{MeOH})$ extract, which was the optimal extract to isolate most of the compounds present in the plant, and to evaluate the hepatoprotective effect $[7,8,10]$. However, traditional medicinal herbs are often used in the form of brandy immersion (equivalent to Ethanol: Water extract $(1 / 1, v / v)$ ). Therefore, this study compared the hepatoprotective effect of the methanol extract (HHM) and the ethanol: water extract 1/1 (HHE-1/1).

\section{Results}

\subsection{Phytochemical Investigation of H. hirsuta}

The dried powder of $\mathrm{H}$. hirsuta $(4 \mathrm{~kg})$ was extracted with $\mathrm{MeOH}(10 \mathrm{~L} \times 3$ times) overnight at room temperature. Evaporation of the solvent under reduced pressure formed a tarry $\mathrm{MeOH}$ residue $(370 \mathrm{~g})$. The $\mathrm{MeOH}$ residue was suspended in $\mathrm{H}_{2} \mathrm{O}$ and successively partitioned with $n$-hexane, $\mathrm{CH}_{2} \mathrm{Cl}_{2}$, EtOAc to yield an $\mathrm{H}(220 \mathrm{~g}), \mathrm{D}(37 \mathrm{~g})$, EtOAc (26 g), and water layer (52 g), respectively. Using combined chromatography separation techniques (Silica gel, RP-18, and Sephadex ${ }^{\mathrm{TM}}$ LH-20), 16 known compounds (1-16), namely 4,5-dihydroblumenol A (1), (+)-syringaresinol (2), indole-3-carboxaldehyde (3), syringaresinol- $\beta$-D-glucoside (4), acariol A2 (5), cucumegastigmane I (6), methyl rosmarinate (7), 2-O- $\beta$-D-glucopyranosyl methyl salicylate (8), dihydrophaseic acid (9), benzyl 2-O- $\beta$-D-glucopyranosyl-2,6-dihydroxybenzoate (10), kaempferol-3- $\beta$-D-(6-O-trans- $p$ coumaroyl)glucopyranoside (11), byzantionoside B (12), citrusin C (13), 20-hydroxyecdysone (14), siringin (15), and 3,4',7,8-tetrahydroxyflavone (16) were isolated from the aerial part of the H. hirsuta (the detailed isolation scheme and chemical structures are shown in Scheme 1). Their structures were determined using the modern spectroscopic method (1D and 2D NMR) and by correlating previously reported data. The results demonstrated that the $\mathrm{MeOH}$ extract of $H$. hirsuta contained many bioactive compounds, including alkaloids, steroids, lignans, and phenolics.

\subsection{Effects of HHM, HHE-1/1 on Hematological Parameters}

At the end of the study, the mean value of red blood cells in the $\mathrm{CCl}_{4}$ group was $8.71 \pm 1.15 \mathrm{~T} \mathrm{~L}^{-1}$. This figure was significantly lower compared with the silymarin group $\left(10.05 \pm 0.91 \mathrm{~T} \mathrm{~L}^{-1}\right)$. The mean value of $\mathrm{HBG}$ in the $\mathrm{CCl}_{4}$ group was $122 \pm 17.91 \mathrm{~g} \mathrm{~L}^{-1}$. This value was significantly lower compared with the control group, silymarin-treated and extracts-treated groups $(p<0.01$ and $p<0.001)$. The mean value of PLT in the $\mathrm{CCl}_{4}$ group $\left(415.3 \pm 137.57 \mathrm{G} \mathrm{L}^{-1}\right)$ was also lower than the control group, HHM group and HHE-1/1 group $\left(604.78 \pm 82.11 \mathrm{G} \mathrm{L}^{-1} ; 577.30 \pm 79.84 \mathrm{G} \mathrm{L}^{-1}\right.$ and $591.10 \pm 106.77 \mathrm{G} \mathrm{L}^{-1}$ respectively) $(p<0.01)$. The mean value of WBC in the control group was lower than in other groups $(p<0.05$ and $p<0.001)$. The highest WBC mean figure belonged to the $\mathrm{CCl}_{4}$-treated group, which was significantly higher than HHM and HHE-1/1 groups $(p<0.001$ and $p<0.05)$ (Table 1). 


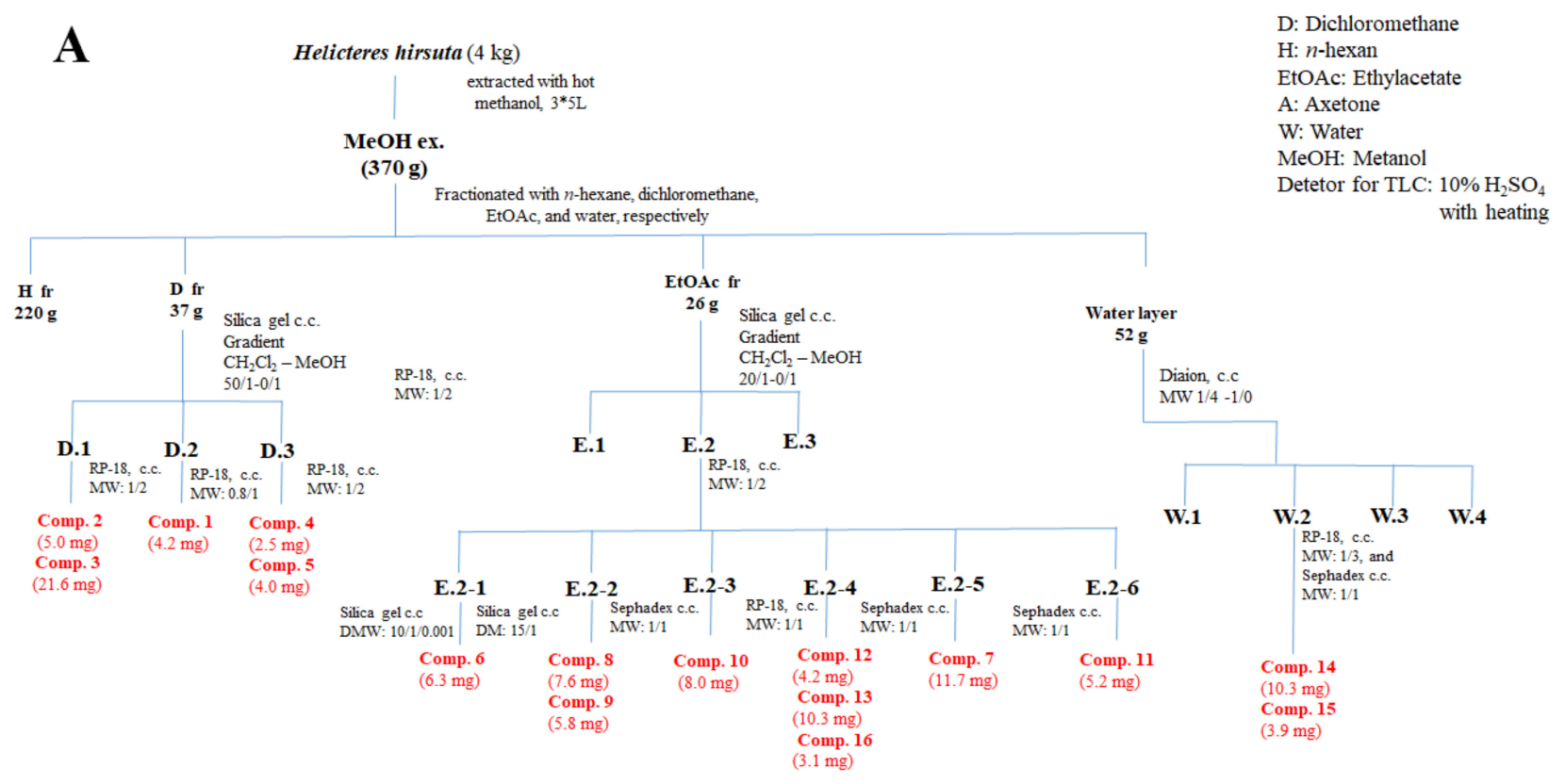

B<smiles>CC(O)/C=C/[C@@]1(C)C(C)CC(=O)CC1(C)C</smiles>

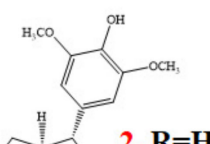

2. $\mathbf{R}=\mathbf{H}$ 4. $\mathrm{R}=\mathrm{Glc}$

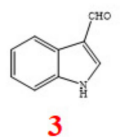

3
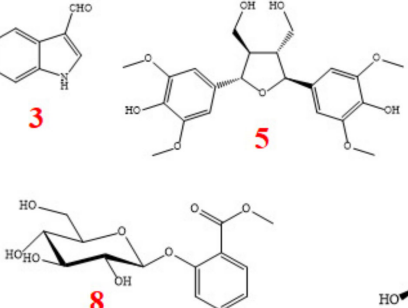

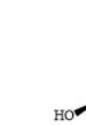<smiles>CCCCCCC(C)C1CC(C)CC(C)C1(C)C</smiles><smiles>CC1=CC(C)[C@H](CCC(C)CC(C)C)C(C)=C1</smiles><smiles>CC(C)C(Cc1ccc(Br)c(Br)c1)OC(=O)/C=C/c1ccc(Br)c(Br)c1</smiles><smiles>CCCC(C)c1cc(O)c(Br)c(O)c1</smiles>
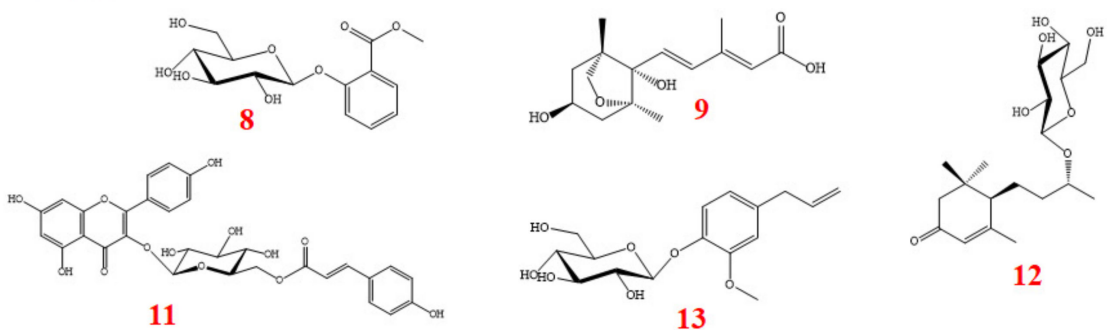

13

11

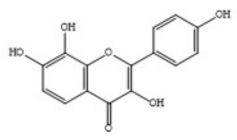

15

Scheme 1. (A) Isolation scheme of the H. hirsuta, and (B) chemical structures of compounds (1-16) isolated from H. hirsuta.

Table 1. HHM and HHE-1/1 effect on red blood cells, hemoglobin, platelets of $\mathrm{CCl}_{4}$-induced liver fibrosis in rats.

\begin{tabular}{|c|c|c|c|c|}
\hline Group $(n=10)$ & $\mathrm{RBC}\left(\mathrm{T} \mathrm{L} \mathrm{L}^{-1}\right)$ & HGB $\left(\mathrm{g} \mathrm{L}^{-1}\right)$ & $\operatorname{PLT}\left(\mathrm{G} \mathrm{L}^{-1}\right)$ & WBC $\left(\mathrm{G} \mathrm{L}^{-1}\right)$ \\
\hline Control & $9.19 \pm 1.38$ & $157.21 \pm 13.48$ & $604.78 \pm 82.11$ & $14.67 \pm 3.13$ \\
\hline $\mathrm{CCl}_{4}$ & $8.71 \pm 1.15$ & $122.00 \pm 17.91^{* * *}$ & $415.30 \pm 137.57^{* *}$ & $26.69 \pm 3.04^{* * *}$ \\
\hline Silymarin & $10.05 \pm 0.91 \# 9.32 \pm 0.84$ & $146.00 \pm 9.78^{\# \#}$ & $542.20 \pm 167.71$ & $23.82 \pm 6.11$ \\
\hline HHM & $9.66 \pm 1.25$ & $153.50 \pm 10.6^{\# \# \#}$ & $577.30 \pm 79.84$ \#\# & $20.52 \pm 2.72 \# \# \#$ \\
\hline HHE-1/1 & & $156.40 \pm 11.6^{\# \# \#}$ & $591.10 \pm 106.77^{\# \#}$ & $22.19 \pm 6^{\#}$ \\
\hline
\end{tabular}

${ }^{* *} p<0.01$ and ${ }^{* * *} p<0.001$ compared with the control group. ${ }^{\#} p<0.05,{ }^{\# \#} p<0.01$ and ${ }^{\# \#} p<0.001$ compared with the CCl group. $^{*}$ 


\subsection{Effects of HHM, HHE-1/1 on Biochemical Parameters}

From the experiment results, there was a considerable upward trend in liver enzyme activity in the four $\mathrm{CCl}_{4}$-treated groups, while the control group was stabilized. It was noticed that enzyme AST activity of three rat groups (silymarin, HHM, and HHE-1/1: $1183.29 \pm 276.57,1076 \pm 398.5$ and $1281.19 \pm 325.15$, respectively) was significantly lower than the $\mathrm{CCl}_{4}$ group $(2234.7 \pm 325.19)(p<0.001)$. The data showed that ALT and GGT activity of the $\mathrm{CCl}_{4}$ group were $903.37 \pm 183.84 \mathrm{u} \mathrm{L}^{-1}$ and $10.1 \pm 3.38 \mathrm{u} \mathrm{L}^{-1}$, respectively. There was a significant increase in ALT and GGT activity of $\mathrm{CCl}_{4}$ group compared with other groups $(p<0.05, p<0.01$ and $p<0.001)$. (Table 2.)

Table 2. HHM and HHE-1/1 effect on liver enzymes activity of $\mathrm{CCl}_{4}$-induced liver fibrosis.

\begin{tabular}{cccc}
\hline Group $(\boldsymbol{n}=\mathbf{1 0})$ & AST $\left(\mathbf{u ~ L}^{-\mathbf{1}}\right)$ & ALT $\left(\mathbf{u ~ L ~ L}^{-\mathbf{1}}\right)$ & GGT $\left(\mathbf{u ~ L}^{-\mathbf{1}}\right)$ \\
\hline Control & $116.97 \pm 19.00$ & $53.55 \pm 12.45$ & $1.70 \pm 2.11$ \\
CCl $_{4}$ & $2234.70 \pm 325.19^{* * *}$ & $903.37 \pm 183.84^{* * *}$ & $10.10 \pm 3.38^{* * *}$ \\
Silymarin & $1183.29 \pm 276.57^{\# \# \#}$ & $730.55 \pm 157.15^{\#}$ & $6.00 \pm 3.74^{\#}$ \\
HHM & $1076.00 \pm 398.50^{\# \# \#}$ & $452.35 \pm 115.73^{\# \# \#}$ & $6.30 \pm 4.40^{\#}$ \\
HHE-1/1 & $1281.19 \pm 325.15^{\# \# \#}$ & $691.26 \pm 161.76^{\#}$ & $5.54 \pm 2.52^{\# \#}$ \\
\hline
\end{tabular}

*** $p<0.001$ compared with the control group. ${ }^{\#} p<0.05,{ }^{\# \#} p<0.01$ and ${ }^{\# \#} p<0.001$ compared with the $\mathrm{CCl}_{4}$ group.

The mean value of the total protein content in the $\mathrm{CCl}_{4}$ group was $68.63 \pm 6.46 \mathrm{~g} \mathrm{~L}^{-1}$. This value was significantly lower than the other groups $(p<0.001, p<0.01)$. The mean concentrations of total bilirubin and direct bilirubin of the control group were: $4.03 \pm 1.0$ and $0.59 \pm 0.32 \mathrm{mmol} \mathrm{L}^{-1}$, respectively, which was significantly lower than the other groups. In addition, the index in the group of rats treated with silymarin was considerably lower than in the model $\mathrm{CCl}_{4}$ group with $p<0.05$ (Table 3).

Table 3. HHM and HHE-1/1 effect on total protein and bilirubin of $\mathrm{CCl}_{4}$-induced liver fibrosis.

\begin{tabular}{cccc}
\hline Group $(\boldsymbol{n = 1 0 )}$ & Total Protein $\left(\mathbf{g ~ L}^{-\mathbf{1}}\right)$ & Total Bilirubin $\left(\boldsymbol{\mu m o l ~ \mathbf { L } ^ { - 1 } )}\right.$ & ${\text { Direct Bilirubin }\left(\boldsymbol{\mu m o l ~ L} \mathbf{L}^{-\mathbf{1}}\right)}$ \\
\hline Control & $79.86 \pm 6.81^{* *}$ & $4.03 \pm 1.00$ & $0.59 \pm 0.32$ \\
CCl $_{4}$ & $68.63 \pm 6.46^{* *}$ & $16.64 \pm 5.03^{* * *}$ & $10.83 \pm 4.97^{* * *}$ \\
Silymarin & $79.69 \pm 6.36^{\# \#}$ & $12.03 \pm 4.71^{\#}$ & $6.36 \pm 3.18^{\#}$ \\
HHM & $79.21 \pm 1.89^{\# \#}$ & $12.57 \pm 5.78$ & $7.59 \pm 4.18$ \\
HHE-1/1 & $77.62 \pm 3.78^{\# \#}$ & $13.55 \pm 5.37$ & $7.84 \pm 4.34$ \\
\hline
\end{tabular}

${ }^{* *} p<0.01$ and ${ }^{* * *} p<0.001$ compared with the control group. ${ }^{\#} p<0.05,{ }^{\# \#} p<0.01$ and ${ }^{\# \# \#} p<0.001$ compared with the $\mathrm{CCl}_{4}$ group. $^{*}$

\subsection{Effects of HHM, HHE-1/1 on Histopathology of the Liver}

The macroscopic images of the rat livers showed the rats' livers of control, silymarintreated and extract-treated groups were red-brown, with a smooth surface, soft density, good elasticity, no lumps, or necrosis. In contrast, the rats' livers of the $\mathrm{CCl}_{4}$ group were yellow-brown, the liver surface was rough with many protrusion nodules of $1-3 \mathrm{~mm}$ in size. Liver density was quite firm (Figure 1). The livers of $\mathrm{CCl}_{4}$ groups were more severely damaged than the other groups. 


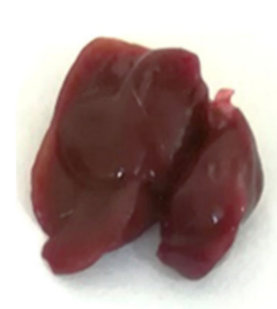

Control group

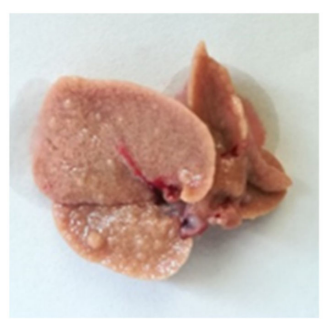

$\mathrm{CCl}_{4}$ group

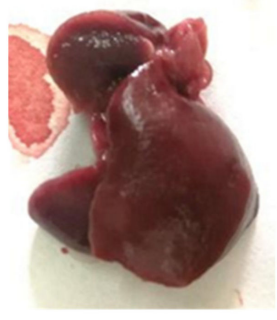

Silymarin group

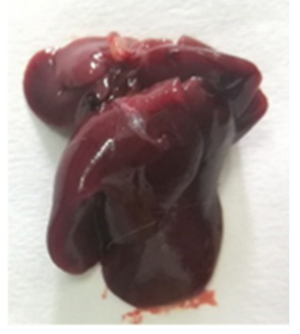

HHM group

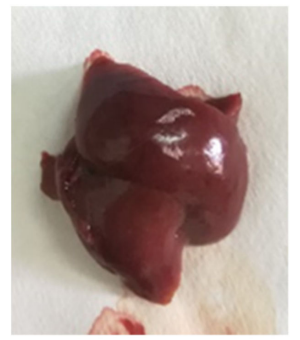

HHE-1/1 group

Figure 1. Photograph of rats' livers of $\mathrm{CCl}_{4}$-induced liver fibrosis model.

The microscopic images of the liver in the control group shows an image of normal liver tissue with a structure of cell bands, and rafts surrounding the central vein of the lobule. Between the bands, the liver rafts are the sinusoid. Some liver cells are slightly degenerated. The portal area contains the bile duct, portal vein, and hepatic artery (Figure 2).
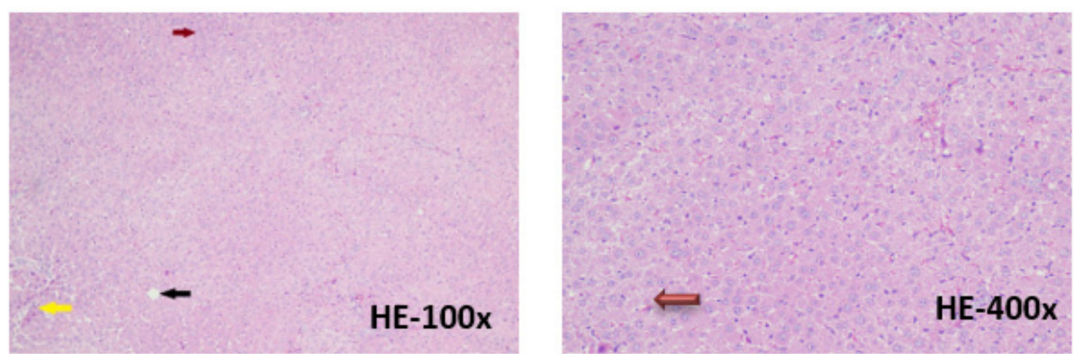

\section{Portal area (yellow arrow), central vein (black arrow), sheets of hepatocytes (brown arrow)}

Figure 2. Photomicrographs of rat liver in control group stained with hematoxylin-eosin.

The microscopic images of the liver in the $\mathrm{CCl}_{4}$ group show that the standard structure of the liver was destroyed. The hepatic parenchyma was separated by the fibrosis septa from the center of the lobule to the portal areas and from the portal areas to the portal areas. Most lobules and the portal areas were invaded by bands of fibrosis; with the regeneration of hepatocytes, they formed pseudo lobules. The central vein of the central lobe was not clearly visible. Many fat degeneration cells, accompanied by infiltrated white blood cells surround the necrotic liver cells. These livers were stage F4 fibrosis [11] (Figure 3).
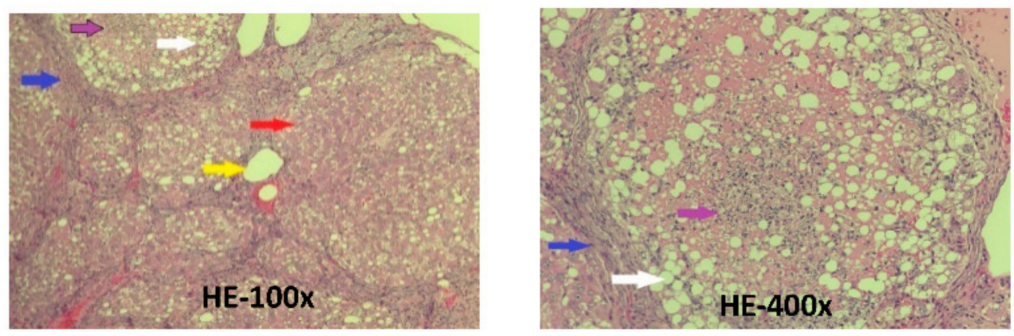

Portal area (yellow arrow), fibrosis band (blue arrow), neoplastic nodule (red arrow), degenerative fatty hepatocytes (white arrow),

globular infiltration around necrotic hepatocytes (purple arrow).

Figure 3. Photomicrographs of rat liver in $\mathrm{CCl}_{4}$ group stained with hematoxylin-eosin.

The microscopic images of livers in the silymarin group and HHM group and HHE1/1 group: the structure was maintained, hepatic parenchyma did not appear in pseudo lobules. However, the appearance of short fibrous bands, extending the portal areas, dissecting the liver parenchyma can be observed. The liver parenchyma of the HHM group 
shows clusters of liver cells with fat and water degeneration, which were observed scattered in silymarin and HHE-1/1 group. These livers were stage F2 fibrosis [11] (Figure 4).
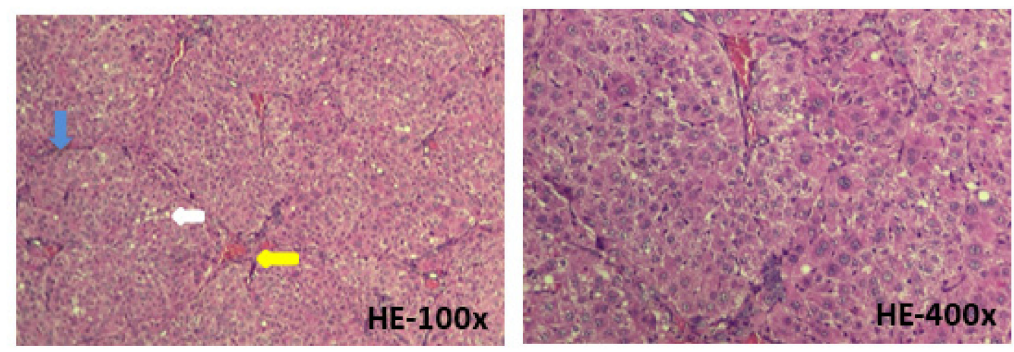

Silymarin group
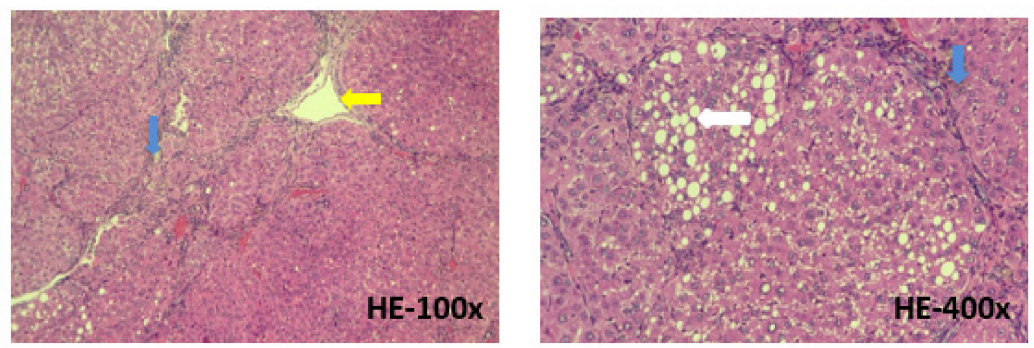

HHM group
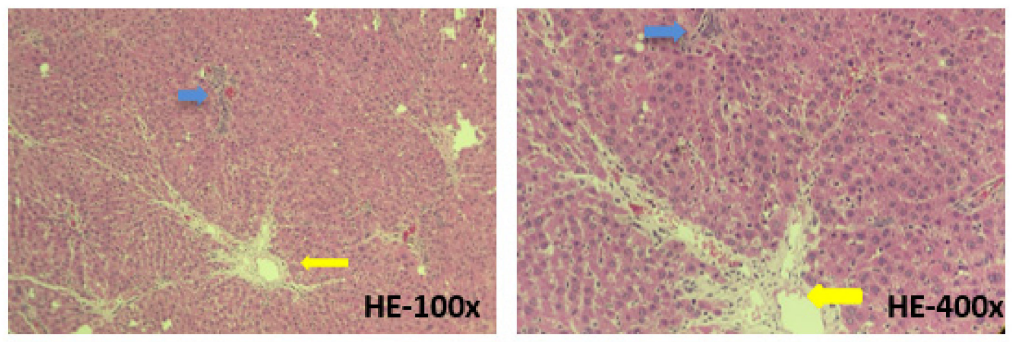

HHE-1/1 group

Portal area (yellow arrow), fibrosis band (blue arrow), degenerative fatty hepatocytes (white arrow).

Figure 4. Photomicrographs of rat liver in silymarin, HHM, HHE-1/1 groups stained with hematoxylin-eosin.

Photomicrographs of a liver of the $\mathrm{CCl}_{4}$ group stained with Masson show (A) a significant increase in collagen (blue) separated the liver lobes to pseudo lobes. The livers of silymarin, HHM, and HHE-1/1 groups appear as short bands of collagen that extended the portal areas. There were no pseudo lobes in the liver parenchyma (Figure 5).

Image analysis by ImageJ software showed the blue area represented by the collagen fiber area in the $\mathrm{CCl}_{4}$ group. The rate of the collagen invasion area accounted for $19.9 \%$ while measurements of the collagen area of the silymarin, HHM and HHE- $1 / 1$ groups were $1.19 \%, 3.44 \%$, and $5.12 \%$, respectively. 

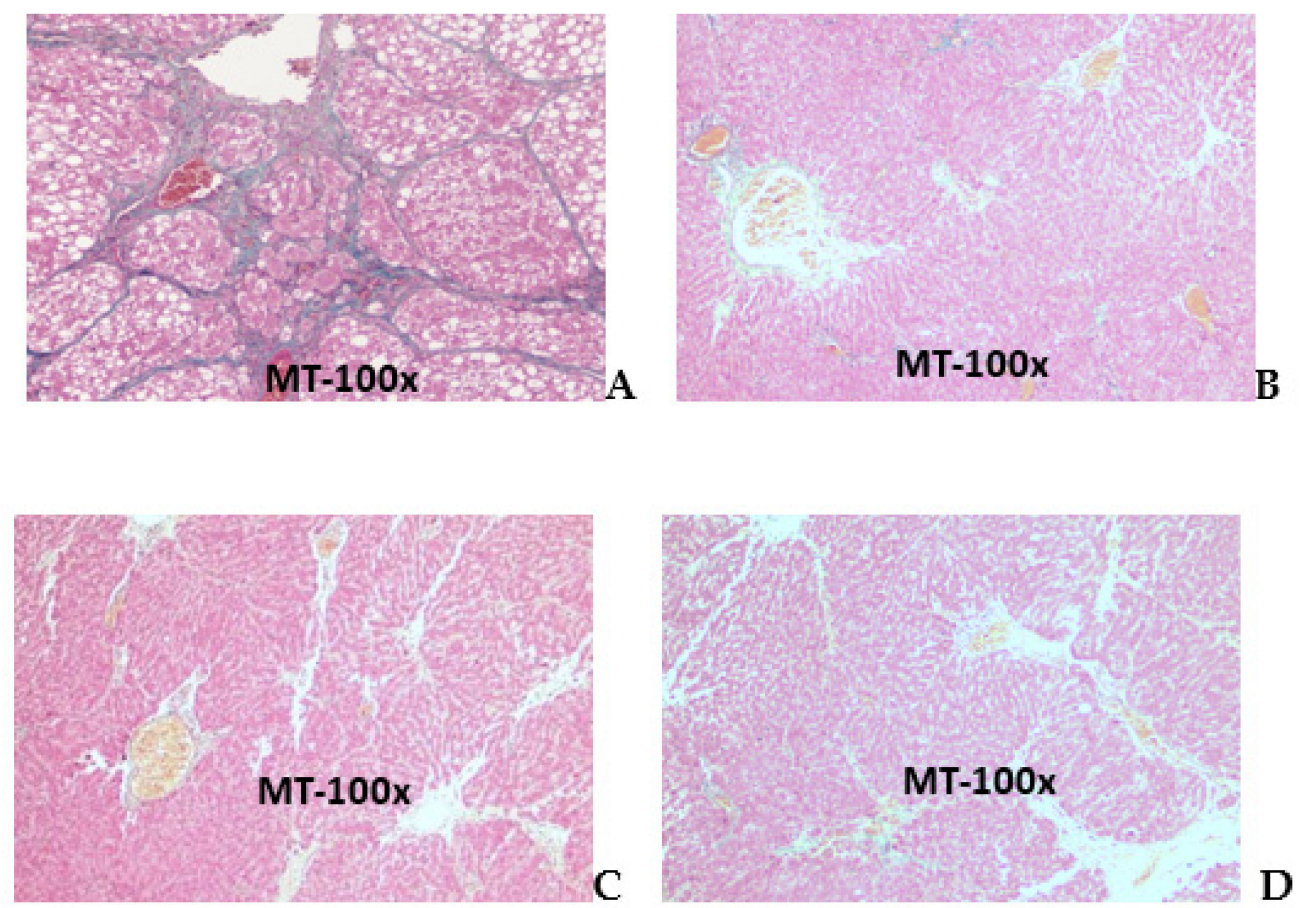

A: CCl4-treated group, B: silymarin group, C: HHM group, D: HHE-1/1 group

Figure 5. Photomicrographs of rat liver stained with Masson trichrome.

\section{Discussion}

\subsection{Effects of HHM, HHE-1/1 on Hematological Parameters}

In cirrhosis, there is often a manifestation of chromatic anemia, a decrease in hemoglobin content, and a reduction in the number of erythrocytes due to the decline in the liver's iron metabolism function, hemophilia, hypersplenism or bone marrow suppression [12]. In this study, the number of erythrocytes showed no substantial difference between the rat groups compared with the control group $(p>0.05)$, so the level of anemia could not be assessed through this parameter. Another parameter to evaluate anemia more accurately is hemoglobin content; in this study, the hemoglobin in the model group of rats' cirrhosis significantly decreased compared with the control group, the silymarin-treated and the extracts-treated groups. These results demonstrated that $\mathrm{CCl}_{4}$ induced anemia in rats and showed the hepatoprotective effects of the silymarin and extracts to maintain the mean hemoglobin in rats.

In cirrhosis, platelet count also tends to decrease due to portal hypertension, splenomegaly, spleen hyperplasia, and coagulation disorder [12,13]. In this study, the number of platelets in the $\mathrm{CCl}_{4}$ group also significantly decreased compared with the control group and the rat group that received silymarin, HHM and HHE-1/1. Our results demonstrate the protective effect of silymarin and H. hirsuta extracts when administered to rats, which can be used as a functional food to protect the liver function.

\subsection{Effects of HHM, HHE-1/1 on Biochemical Parameters}

The activity of enzymes AST, ALT, and GGT is also important in the evaluation of liver damage in the study. The results of this study showed that the control group had a normal level of these three enzymes while the other groups experienced a sharp increase in the activity of these enzymes. This result means that hepatocytes were significantly damaged in rats injected with $\mathrm{CCl}_{4}$. In more detail, AST activity of the $\mathrm{CCl}_{4}$ group was higher than in the groups of rats which were injected $\mathrm{CCl}_{4}$ and received oral silymarin or HHM or HHE-1/1. This result suggests that all three of the medicine materials used showed the ability to reduce the AST activity. In terms of ALT activity, only the silymarin- 
treated group of rats had a significantly lower ALT activity than the $\mathrm{CCl}_{4}$ group. On the model of rats' liver cirrhosis by $\mathrm{CCl}_{4}$, Xiang Lan Wei et al. studied the hepatoprotective effects of pomegranate peel and seed extract [14], and Yuan Yuan Zhan et al. studied the hepatoprotective effects of melon seed extract [15], the results showed that the extracts were more effective in reducing liver enzymes than the model group. This study showed that GGT of the $\mathrm{CCl}_{4}$ group was higher than the silymarin, HHM, and HHE-1/1 groups. This result can be explained because HHM and HHE-1/1 both have protective effects, stabilize the hepatocellular membrane and inhibit the ingress of toxins into cells. Silymarin has a similar effect [16].

The majority of proteins in the blood plasma are synthesized by the liver. When the liver is in cirrhosis, the liver function is decreased, so there is a reduction in protein in plasma. In this study, the total protein in the $\mathrm{CCl}_{4}$ group was lower than that of all other groups. These results suggest that the liver function of the $\mathrm{CCl}_{4}$ group was reduced compared with the other groups. Bilirubin is a liver metabolic product. Bile duct obstruction by cirrhosis causes bilirubin to not be delivered to the small intestine, so they are absorbed into the blood. An increase in bilirubin in the blood is a consequence. In this study, the total and direct bilirubin of the $\mathrm{CCl}_{4}$ injection groups were higher than the control group and silymarin-treated group, reflecting the liver damage of rats injected with $\mathrm{CCl}_{4}$. Silymarin demonstrates the ability to be effectively hepatoprotective.

\subsection{Effects of HHM, HHE-1/1 on Histopathology of the Liver}

The study's results showed that: All livers of the control group had normal parenchyma, whereas all livers of $\mathrm{CCl} 4$ group had cirrhosis at the end of the experiment (cirrhosis stage F4). The rats' group was injected with $\mathrm{CCl}_{4}$ and received silymarin or HHM or HHE-1/1 livers, A histological image showed that livers had fibrosis at F1-F2 stage.

In addition, the Masson trichrome staining image showed that the collagen areas in the livers of the $\mathrm{CCl}_{4}$ group (19.9\%) were significantly higher than the silymarin group (1.19\%), HHM (3.44\%), and HHE-1/1 (5.12\%). This result proved that the collagen deposition in the liver of the $\mathrm{CCl}_{4}$ group was higher than in other groups; this is an important indicator to evaluate the level of liver fibrosis. Silymarin, HHM, HHE-1/1 were used to help alleviate the deposition of collagen in the liver parenchyma and prevent fibrosis of the liver. The study on the hepatoprotective effects of pomegranate peels and seeds by Xiang-Lan Wei also showed that the collagen deposition in the toxic group with $\mathrm{CCl}_{4}$ was higher than in the group treated with pomegranate peels and seeds extracts [14].

The above results showed that both HHM and HHE-1/1 were effective hepatoprotectives, reducing the effect of $\mathrm{CCl}_{4}$ on the liver, and slowing the progression leading to cirrhosis in rats, which is an effect similar to a silymarin dose of $0.2 \mathrm{~g} \mathrm{~kg}^{-1} \mathrm{BW}$.

\section{Materials and Methods}

\subsection{Materials}

The aerial part of the Helicteres hirsuta Lour. was collected at A Luoi, Phong Dien district, Thua Thien Hue province, Vietnam in March 2019, and identified by Dr. Vu Tien Chinh, Vietnam National Museum of Nature, VAST. A voucher specimen (HH 01) was deposited at the Mientrung Institute for Scientific Research, VAST, and Vietnam Military Medical University. The medicinal herb was collected and put in a sealed plastic bag and brought to the laboratory, then chopped into sections of about $3 \mathrm{~cm}$, dried in the Etuves XU250 oven at $45^{\circ} \mathrm{C}$ temperature to constant weight. Materials were powdered before studying.

\subsection{Chemicals and Equipment}

Chemicals

Methanol, ethanol, carbon tetrachloride $\left(\mathrm{CCl}_{4}\right)$, and olive oil are from Merck-Germany; chemical hematology is by Nihon Kohden; the biochemical test kit is from the Beckman Coulter firm. Legalon 140 (140 mg silymarin) is from MADAUS GmbH, Germany. 


\section{Animals}

Fifty adult Wistar rats were of both sexes, with no pregnancies, and weights of $200 \pm 20 \mathrm{~g}$. The healthy, agile, and fluffy animals were kept in stainless steel cages in rooms maintained at $25{ }^{\circ} \mathrm{C}$ on 12-h light/dark cycles and provided free access to standard diet and water. The experimental procedures were approved by the Animal Ethics Committee and animal experiments were carried out per the approved protocols $[8,10]$.

\subsection{Extraction Methods}

The methanol extract of H. hirsuta L. (HHM) method is as follows: $10 \mathrm{~kg}$ of powder was extracted with methanol $(3 \times 20 \mathrm{~L})$ at $25^{\circ} \mathrm{C}$ for $72 \mathrm{~h}$. After the mixture was filtered the methanol solution was obtained. This solution was evaporated in a rotary evaporator. A total of $960 \mathrm{~g}$ of $\mathrm{HHM}$ was obtained and stored at $4{ }^{\circ} \mathrm{C}$ during the experiment.

The ethanol extract of $H$. hirsuta L. (HHE-1/1) method is as follows: $10 \mathrm{~kg}$ of powder was extracted with ethanol/water 1/1: $v / v(3 \times 20 \mathrm{~L})$ at $25^{\circ} \mathrm{C}$ for $72 \mathrm{~h}$. After the mixture was filtered and the ethanol solution was obtained. This solution was evaporated in a rotary evaporator. A total of $850 \mathrm{~g}$ of $\mathrm{HHE}-1 / 1$ was obtained and stored at $4{ }^{\circ} \mathrm{C}$ during the experiment.

Before giving to rats to administer, HHM and HHE-1/1 were diluted with distilled water at the rate of 1/4: $w / w$ and used for $3 \mathrm{~h}$.

Hepatoprotective effects of the extract on liver fibrosis induced by $\mathrm{CCl}_{4}$.

Following two weeks of acclimatization, 50 Wistar rats of both sexes were randomly divided into 5 groups of 10 animals each $(n=10)$.

Group 1 (control group) received a daily oral dose of $10 \mathrm{~mL} \mathrm{kg-1} \mathrm{BW} \mathrm{distilled} \mathrm{water}$ and injected subcutaneously (i.s.) with $2 \mathrm{~mL} \mathrm{~kg}^{-1} \mathrm{BW}$ of olive oil twice a week (Tuesday and Friday) for 12 weeks.

Group 2, 3, 4, and 5 rats were i.s. with $2 \mathrm{~mL} \mathrm{~kg}^{-1} \mathrm{BW} \mathrm{CCl}_{4}\left(\mathrm{CCl}_{4}\right.$ diluted to $50 \%$ in olive oil) twice a week (Tuesday and Friday) for 12 weeks. Group $2\left(\mathrm{CCl}_{4}\right.$ group), 3 (silymarin group), 4 (HHM group), and 5 (HHE-1/1 group) received a daily oral dose of $10 \mathrm{~mL} \mathrm{~kg}{ }^{-1}$ BW of distilled water, $0.2 \mathrm{~g} \mathrm{~kg}^{-1}$ BW of silymarin, $1.34 \mathrm{~g} \mathrm{~kg}^{-1} \mathrm{BW}$ of HHM, $1.19 \mathrm{~g} \mathrm{~kg}^{-1} \mathrm{BW}$ of HHE-1/1, respectively.

Distilled water, the solution of silymarin, HHM, and HHE-1/1 were administered to the stomach of the rats with a tip needle once daily in the morning before feeding.

After 48-60 h of $\mathrm{CCl}_{4}$ injection for the last dose, rats' blood was collected to assess biochemical and hematological tests. The rats were anesthetized by cervical dislocation; their abdomens were opened to observe the gross pathological liver. A lobe of liver tissue from each rat was collected. Biochemical tests were performed by the Beckman coulter AU480 machine. Hematology tests were performed by the Nihon Kohden MEK-7300K machine. The liver samples were stained with hematoxylin and eosin (HE) and Masson trichrome (MT) for histopathological examination.

\subsection{Statistical Analysis}

The data of the experiment were expressed as the means $\pm S D$, and were analyzed via Excel 16.0 and the SPSS 20.0 software. The Student's $t$-test was used in the groups' comparison.

\section{Conclusions}

Our liver protective effective results show that treatment with HHM $\left(1.34 \mathrm{~g} \mathrm{~kg}^{-1}\right.$ BW) or HHE-1/1 (1.19 $\left.\mathrm{g} \mathrm{kg}^{-1} \mathrm{BW}\right)$ protected the liver against fibrosis caused by $\mathrm{CCl}_{4}$ on rats. The effects of the extracts are similar to a silymarin dose of $0.2 \mathrm{~g} \mathrm{~kg}^{-1} \mathrm{BW}$. The results revealed that all the livers of the model group had stage F4 cirrhosis; the group that received silymarin, and $\mathrm{HHM}$ and $\mathrm{HHE}-1 / 1$ had milder liver damage cirrhosis at stage F1-F2, which implies that the methanolic and ethanolic extracts of $H$. hirsuta have a definite advantage in the development of oral medications for hepatoprotective activity. 
Author Contributions: Conceptualization, D.T.H. and T.T.H.T.; methodology, N.V.D.; investigation, T.T.D.; resources, L.B.V.; data curation, S.Y.Y.; writing—original draft preparation, D.T.H. and T.T.H.T.; writing-review and editing, G.D., L.T.A., and L.T.A.H. All authors have read and agreed to the published version of the manuscript.

Funding: This research received no external funding.

Institutional Review Board Statement: The study was conducted according to the guidelines and approved by the Animal Ethics Committee in Chungnam National University (202003A-CNU-062).

Informed Consent Statement: Not applicable.

Data Availability Statement: Not applicable.

Conflicts of Interest: The authors declare no conflict of interest.

\section{References}

1. Gerush, O.V.; Iakovlieva, L.; Yu Koshova, O.; Spiridonov, S.O. Investigation of the mechanism of action of new hepatoprotective herbal drugs in the experiment. J. Glob. Pharma Technol. 2018, 10, 397-409.

2. Zhou, W.-C.; Zhang, Q.-B.; Qiao, L. Pathogenesis of liver cirrhosis. World J. Gastroenterol. 2014, 20, 7312-7324. [CrossRef] [PubMed]

3. Chi, V.V. Dictionary of Vietnamese medicinal plants. Biol. Pharm. Bull. 2012, 2, 1010-1013.

4. $\quad$ Le Trung Hieu, L.L.S.; Nhung, N.M.; Vi, V.T.T.; Van Thi, T.T. Determination of methyl gallate and rutin from Helicteres hirsuta by HPLC and using methyl gallate content as a marker for the evaluation of antioxidant capacity. Vietnam J. Chem. 2018, 56, 342-346.

5. Pham, H.N.T.; Vuong, Q.V.; Bowyer, M.C.; Scarlett, C.J. Phytochemical profiles and antioxidant capacity of the crude extracts, aqueous- and saponin-enriched butanol fractions of Helicteres hirsuta Lour. leaves and stems. Chem. Pap. 2017, 71, $2233-2242$. [CrossRef]

6. Pham, H.N.T.; Vuong, Q.V.; Bowyer, M.C.; Scarlett, C.J. Optimization of ultrasound-assisted extraction of Helicteres hirsuta Lour for enhanced total phenolic compound and antioxidant yield. J. Appl. Res. Med. Aromat. Plants 2017, 7, 113-123. [CrossRef]

7. Vinh, L.B.; Nguyet, N.T.M.; Yang, S.Y.; Kim, J.H.; Thanh, N.V.; Cuong, N.X.; Nam, N.H.; Minh, C.V.; Hwang, I.; Kim, Y.H. Cytotoxic triterpene saponins from the mangrove Aegiceras corniculatum. Nat. Prod. Res. 2019, 33, 628-634. [CrossRef] [PubMed]

8. Nguyen, T.M.N.; Lomunova, M.; Vu, T.P.D.; Le, B.V.; Kim, Y.H.; Kang, J.S.; Hwang, I. Anti-allergic effects of the ethanol extract of Syzygium formosum (Wall.) Masam leaves and its immunoregulatory mechanisms. J. Ethnopharmacol. 2018, 211, 171-179. [CrossRef] [PubMed]

9. Nguyen Viet, D.; Le Ba, V.; Nguyen Duy, T.; Pham Thi, V.A.; Tran Thi, H.; Le Canh, V.C.; Bach Long, G.; Kim, Y.H.; Tuan Anh, H.L. Bioactive compounds from the aerial parts of Hypericum sampsonii. Nat. Prod. Res. 2021, 35, 646-648. [CrossRef] [PubMed]

10. Vinh, L.B.; Nguyet, N.T.M.; Ye, L.; Dan, G.; Phong, N.V.; Anh, H.L.T.; Kim, Y.H.; Kang, J.S.; Yang, S.Y.; Hwang, I. Enhancement of an in vivo anti-inflammatory activity of oleanolic acid through glycosylation occurring naturally in Stauntonia hexaphylla. Molecules 2020, 25, 3699. [CrossRef] [PubMed]

11. Nallagangula, K.; Shashidhar, K.N.; Lakshmaiah, V.; Muninarayana, C. Liver fibrosis: A compilation on the biomarkers status and their significance during disease progression. Future Sci. OA 2017, 4, FSO250. [CrossRef] [PubMed]

12. Qamar, A.A.; Grace, N.D. Abnormal hematological indices in cirrhosis. Can. J. Gastroenterol. 2009, 23, 441-445. [CrossRef] [PubMed]

13. Bashour, F.N.; Teran, J.C.; Mullen, K.D. Prevalence of peripheral blood cytopenias (hypersplenism) in patients with nonalcoholic chronic liver disease. Am. J. Gastroenterol. 2000, 95, 2936-2939. [CrossRef] [PubMed]

14. Wei, X.L.; Fang, R.T.; Yang, Y.H.; Bi, X.Y.; Ren, G.X.; Luo, A.L.; Zhao, M.; Zang, W.J. Protective effects of extracts from Pomegranate peels and seeds on liver fibrosis induced by carbon tetrachloride in rats. BMC Complement. Altern. Med. 2015, 15, 389. [CrossRef] [PubMed]

15. Zhan, Y.Y.; Wang, J.H.; Tian, X.; Feng, S.X.; Xue, L.; Tian, L.P. Protective effects of seed melon extract on CCl(4)-induced hepatic fibrosis in mice. J. Ethnopharmacol. 2016, 193, 531-537. [CrossRef] [PubMed]

16. Vargas-Mendoza, N.; Madrigal-Santillán, E.; Morales-González, A.; Esquivel-Soto, J.; Esquivel-Chirino, C.; García-Luna, Y.; González-Rubio, M.; Gayosso-de-Lucio, J.A.; Morales-González, J.A. Hepatoprotective effect of silymarin. World J. Hepatol. 2014, 6, 144-149. [CrossRef] [PubMed] 